\title{
Alagille Sendromu'na Eşlik Eden Kronik Böbrek Yetmezliği: Olgu Sunumu
}

Alagille Syndrome Presenting With Chronic Renal Failure: Case Report

\author{
Selahattin AKAR *, Sevilay TOPÇUOĞLU * \\ Dilek YAVUZCAN ÖZTÜRK *, Güner KARATEKİN *, Fahri OVALI *
}

(*) Zeynep Kamil Kadın ve Çocuk Hastalıkları Eğt. ve Arş. Hastanesi, Yenidoğan Yoğun Bakım Ünt, İstanbul, Türkiye.

\section{$\ddot{O Z Z T}$}

Giriș: Alagille Sendromu intrahepatik safra yolları tutulumu, konjenital kalp hastalığı, göz anomalile$r i$, iskelet ve santral sinir sistemi tutulumu,böbrek anomalileri ve tipik yüz görünümü ile karakterize otozomal dominant geçişli bir sendromdur.

Olgu: Antenatal takiplerinde sağ hipoplastik böbrek saptanan klz bebek doğumdan hemen sonra tetkik ve tedavi için yenidoğan yoğun bakım ünitesine yatırlldı. Jagged 1 gen mutasyonu saptanan 5 ayllk kardeşinin karaciğer ve böbrek yetmezliği nedeniyle vefat ettiği ögrenildi. Olgumuzda da total bilirubin ve direkt bilirubin hakimiyeti mevcuttu. Renal ultrasonografisi bilateral displastik böbrekle uyumlu olarak rapor edildi. Ekokardiyografisinde periferik pulmoner stenoz, göz muayenesinde posterior embryotokson saptandi. Hastanin uzun süren fungal peritoniti nedeniyle karaciğer biyopsisi yapılamad ancak hastada anamnez, klinik ve laboratuar bulgulartyla bilateral displastik böbreğe bağlı kronik böbrek yetmezliği ile birlikte olan Alagille Sendromu düşünüldü.

Sonuç: Nadir saptanan bilateral displastik böbreğe bağlı kronik böbrek yetmezliği ile birlikte olması nedeniyle sunmak istedik.

Anahtar kelimeler: Alagille Sendromu, displastik böbrek, böbrek yetmezligi i.

\section{ABSTRACT}

Introduction: Alagille syndrome is an autosomal dominant disorder that affects intrahepatic bile ducts, skeletal, renal, cardiac, and central nervous system and characterized with typical facial appearance.

Cases: A female newborn with the antenatal diagnosis of right hypoplastic kidney was hospitalized following the birth. One of her siblings with Jagged 1 mutation has died because of renal and liver failure. Our case had total and direct hyperbilirubinemia. Renal ultrasonography revealed bilateral dysplastic kidney. Peripheral pulmonary stenosis was diagnosed with echocardiography. She has posterior embryotoxon on eye examination. Although liver biopsy could not be performed because of fungal peritonitis, Allagille syndrome with the renal failure secondary to bilateral dysplastic kidney was thought with the family history, clinical and laboratory findings.

Conclusion: We presented this atypical case coinciding with bilateral congenital dysplastic kidneys and chronic renal failure.

Key words: Alagille syndrome, dysplastic kidney, renal failure.

\author{
İletişim Bilgileri: \\ Yazışmadan Sorumlu Yazar: Selahattin AKAR \\ Yazışma Adresi: Zeynep Kamil Kadın ve Çocuk Hasta- \\ lıkları Eğt. ve Arş. Hastanesi İstanbul, Türkiye. \\ Tel: +90 2163910680 \\ E-mail: selahattinakar2001@yahoo.com \\ Makalenin Geliş Tarihi: 14.08.2014 \\ Makalenin Kabul Tarihi: 22.11.2014
}




\section{GİRIŞ}

Alagille Sendromu(AGS) intrahepatik safra yolları tutulumu,konjenital kalp hastalığı,göz anomalileri,iskelet ve santral sinir sistemi tutulumu,böbrek anomalileri ve tipik yüz görünümü ile karakterize, otozomal dominant geçişli bir sendromdur.Bu sendromda farklı böbrek anomalileri bildirilmesine rağmen karaciğer tutulumu ve konjenital kalp hastalıkları kadar s1k değildir.Burada displastik böbrek zemini üzerinde gelişen kronik böbrek yetmezliği ile karakterize bir AGS olgusu tartışılmıştır.

\section{OLGU}

Antenatal takiplerinde sağ hipoplastik böbrek saptanan hasta doğumdan hemen sonra tetkik ve tedavi için yenidoğan yoğun bakım ünitesine yatırıldı. Yeni Ballard skorlamasına göre 33 haftalık olan bebeğin ağırlı̆̆ 1770 gram (10-25 persentil), boyu $44 \mathrm{~cm}$ (50 persentil), baş çevresi $30 \mathrm{~cm}$ (10-50 persentil) idi. Anne baba arasında akrabalık mevcuttu (hala-day1 çocukları). Jagged 1 gen mutasyonu saptanan 5 aylık kardeşinin karaciğer ve böbrek yetmezliği nedeniyle vefat ettiği öğrenildi. Yatışında kardiyovasküler sistem, solunum sistemi ve batın muayenesi normal idi. Haricen kız, doğal görünümde idi. Minimal enteral beslenme başlanan hastaya, intravenöz sıvı desteği sağlandı. Tam kan sayımı ve tam idrar tahlili tetkiklerinde özellik yoktu. Postnatal 32. saatinde belirgin ödemleri artan ve idrar miktarı $<1 \mathrm{ml} / \mathrm{kg} /$ saat olan hastanın kanda BUN:20,1 mg/dl, kreatinin: 2,9 mg/dl, Na: $134 \mathrm{meq} / \mathrm{L}, \mathrm{K}: 6 \mathrm{meq} / \mathrm{L}, \mathrm{CI}$ : $109 \mathrm{meq} / \mathrm{L}$ olmasi üzerine furosemid tedavisi başland1. Klinik izleminde postnatal 4. gününde potasyum $7 \mathrm{meq} / \mathrm{L}$ ve kreatinin $3,5 \mathrm{mg} / \mathrm{dl} \mathrm{ol-}$ mas1, furosemid, salbutamol, insülin +dekstroz tedavisiyle potasyumun düşmemesi, idrar çık1şının $<1 \mathrm{ml} / \mathrm{kg} / \mathrm{saat}$ ve glomeruler filtrasyon hızı (GFR) $4 \mathrm{ml} / \mathrm{dk} / 1,73 \mathrm{~m}^{2}$ olması üzerine hastaya periton diyalizi açıldı. Batın ultrasonografisinde hepatosplenomegali saptanmad1, bilateral displastik böbrekle uyumlu olarak rapor edildi. Postnatal beşinci gününde üfürümü ortaya çıkan hastanın ekokardiyografisinde periferik pulmoner stenoz, göz muayenesinde posterior embryotokson saptand1. Postnatal 15. gününde kontrol biyokimyasında BUN:15,6 mg/ dl, kreatinin:1,8 mg/dl, Na:136 meq/L, K:4,9 meq/L, CI:107 meq/L, total bilirubin $9,0 \mathrm{mg} / \mathrm{dl}$, direkt bilirubin 3,7 mg/dl, AST $100 \mathrm{U} / \mathrm{L}$, ALT $26 \mathrm{U} / \mathrm{L}$, GGT $86 \mathrm{U} / \mathrm{L}$, ALP $1213 \mathrm{U} / \mathrm{L} \mathrm{Ca} \mathrm{8,9}$ $\mathrm{mg} / \mathrm{dl}, \mathrm{P} 6,4 \mathrm{mg} / \mathrm{dl}$ bulundu. İdrar çıkışı $<1 \mathrm{ml} /$ $\mathrm{kg} /$ saat seyretti. Postnatal 16. günde TSH 19 $\mathrm{mU} / \mathrm{L}$, sT4: 0,8 ng/dl saptanan hastaya L-tiroksin tedavisi başlandi. Hepatit $\mathrm{B}, \mathrm{CMV}, \mathrm{EBV}$,
TORCH serolojisi, alfa-1 antitripsin düzeyleri, serum immunglobulin düzeyleri, vertebra grafileri, ter testi sonuçları normaldi. Kranial ultrasonografisinde patoloji saptanmadı. Hastanın uzun süren Candida albicans peritoniti nedeniyle karaciğer biyopsisi yapılamadı ve hemodiyaliz şansı olmadi. Hastada anamnez, klinik ve laboratuar bulgulariyla bilateral displastik böbreğe bağlı kronik böbrek yetmezliği ile birlikte olan Alagille Sendromu düşünüldü. Postnatal 69. gününde hasta septik şok nedeniyle kaybedildi.

\section{TARTIŞMA}

Arteriohepatik displazi olarak da bilinen Alagille Sendromu intrahepatik safra yolları tutulumu, konjenital kalp hastalığı, göz anomalileri, iskelet ve santral sinir sistemi tutulumu, böbrek anomalileri ve tipik yüz görünümü ile karakterize otozomal dominant geçişli bir sendromdur. Karaciğer ve safra yolları tutulumu olarak kronik kolestaz bulguları sık görülür $(1,2)$. Alagille sendromunda safra kanalındaki azlık \%76'ya varan oranlar bildirilmiştir (3). İndirekt hiperbilirubinemi, yükselmiş karaciğer enzimleri, koagulasyon parametreleririnde yükseklik, yüksek GGT, ALP ve kolesterol tipik laboratuvar bulgularıdır. Hepatomegali \%93-\%100, splenomegali \%70 olguda saptanabilir. Kolestaz bulguları ortaya çıktığında tanı için karaciğer biyopsisi şart değildir. Karaciğer biyopsisi yapılan olgularda çoğunlukla safra yollarında azlik, duktal proliferasyon, portal inflamasyon saptanır ve bu tür olgular yanlışlıkla biliyer atrezi tanıs1 alabilirler. Karaciğer yetmezliği, karaciğer transplantasyonu ve siroza yol açan progresif karaciğer hastalığ $\% 15$ 'inde görülür (4). Olguların çok az bir kisminda karaciğer hastalığı bulgusu yoktur (5). Olgumuzun laboratuvar tetkikinde total bilirubin ve direkt bilirubin hakimiyeti mevcuttu. Serum kolesterol ve koagulasyon parametreleri normal değerlerde idi, GGT 86 U/L, ALP $1213 \mathrm{U} / \mathrm{L}$ idi. Olgumuzun fizik muayenesinde ve ultrasonografik olarak hepatosplenomegali saptanmadi.

Alagille sendromundaki yüz özellikleri belirgin alın, belirgin ve geniş kulak, derin yerleşimli gözler, 1 lımlı hipertelorizm, sivri ve küçük çene, semer burundur. Bu kombinasyon yüze üçgen yüz görünümü verir. Yüz özellikleri major bulgular arasında yer alır ancak özellikle gözlerin derin yerleşimli olup olmamasına göre fenotip değişken olabilir (6). En sık saptanan iskelet bulgusu segmentasyon anomalisi olarak kelebek vertebra saptanır. Bu anomali normal insanlarda ya da diğer multisistemik genetik 
hastalıklarda da görülebilir (VACTER, Crouzon Hastalığı, Kabuki, Jarcho- Levin spondilokostal displazi gibi) (7). Kelebek vertebra dişında hemivertebra, lumbal vertebra aralıklarında darılma, spina bifida okulta görülebilir (8). Kraniosinostoz ve radioulnar sinostoz da bildirilmiştir $(9,10)$. Ancak bizim olgumuzda tipik üçgen yüz görünümü yoktu ve iskelet anomalisi saptanmad1 (Resim 1).

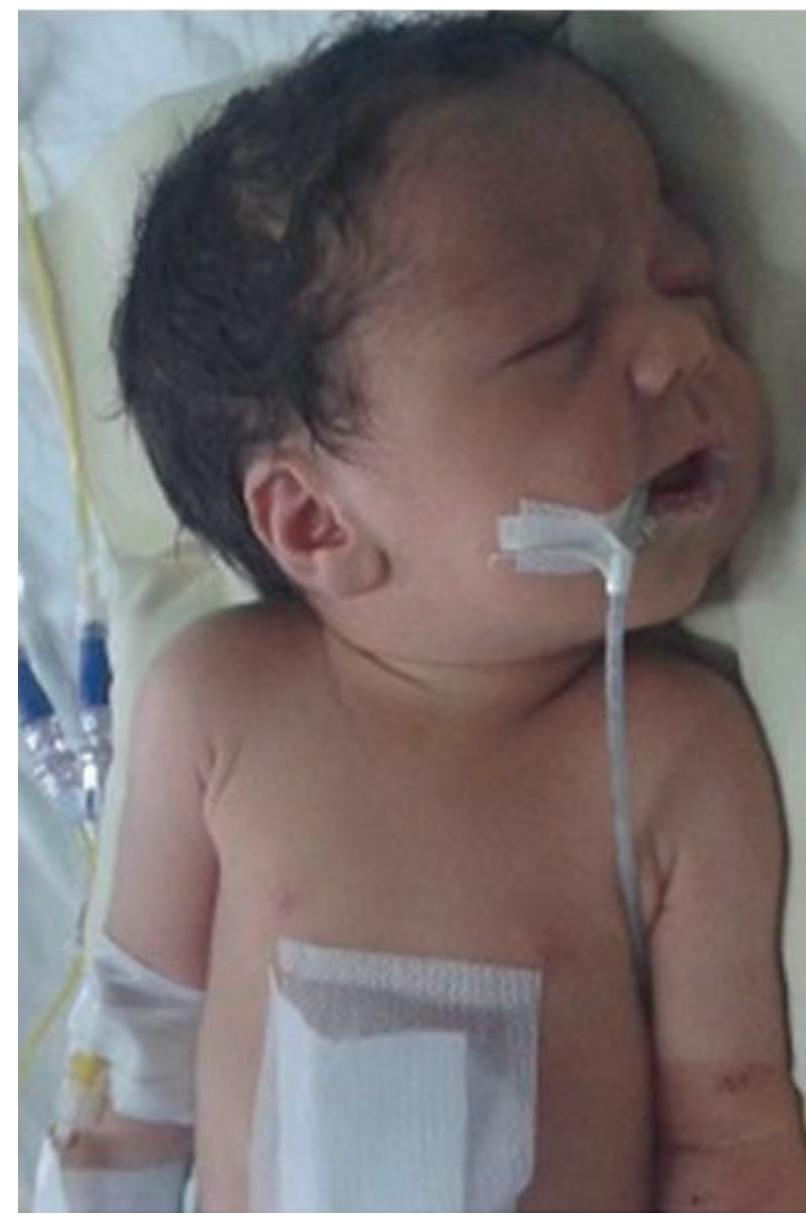

Resim 1: Alagille sendromunda yüze üçgen yüz görünümü veren belirgin alın, belirgin ve geniş kulak, derin yerleşimli gözler, 1lımlı hipertelorizm, sivri ve küçük çene, semer burun olgumuzda yoktu.

Renal anomaliler olguların \%45-60'nda görülmektedir $(11,12)$. Anatomik ya da fonksiyonel renal bozukluk görülebilir. Displastik böbrek renal anomaliler içerisinde en sık olan olarak bildirilmiştir. Vezikoüreteral reflü, hidronefroz, soliter böbrek, ektopik böbrek, bifid pelvis, çift toplayıcı sistem, renal lipidozis gösterilebilir. Küçük böbrek, unilateral ya da bilateral multikistik ya da displastik böbrekler akut veya kronik renal yetmezlik ile ya da yetmezlik olmadan görülebilir $(2,11,13)$. Renal arter stenozuna sekonder sistemik hipertansiyon bildirilmiștir (14). Süt çocukluğu döneminde renal tubuler asidoz, neonatal renal yetmezlik, tübüler atrofi ile tübülointertisyel nefropati ve intertisyel fibrozis rapor edilmiştir $(15,16)$. Erişkin yaşlarda renal yetmezlik gelişir ve sıklıkla renal transplant gerekir (15). Bizim hastamızda da renal patoloji olarak bilateral displastik böbrek bulunması, nadir olmakla beraber, literatürdeki bu bilgiler ile uyumluydu.

Alagille sendromlu olguların yaklaşık \%97'sinde Jagged1 gen mutasyonu saptanır. İkinci s1kl1kta NOTCH2 gen mutasyonu saptanır $(17,18)$. Her iki gen de NOTCH sinyal yolunda anjiogenezden sorumlu genlerdir. $\mathrm{Bu}$ nedenle olguların çoğunda kardiyak anomaliler ve intrakraniyal vasküler malformasyonlar görülmektedir (19). Kardiyak anomali olarak periferik pulmoner stenoz olguların \%90'nında görülebilmektedir. Kompleks kardiyak anomali olarak Fallot tetralojisi görülebilmektedir (18). Posterior embryotokson AGS'da en sik görülen göz bulgusudur. Mikrokornea, keratokonus, stromal hipoplazi, bant keratopati ve katarakt da bildirilmiştir (20). Olgumuzun ekokardiyografisinde periferik pulmoner stenoz, göz muayenesinde posterior embryotokson saptandi.

Her ne kadar genetik analiz yapılmasına imkan olmadiysa da, daha önce Jagged 1 gen mutasyonu saptanan 5 aylık bir kardeşinin karaciğer ve böbrek yetmezliği nedeniyle vefat etmiş olması, kolestaz bulgularının olması, ekokardiyografisinde periferik pulmoner stenoz, göz muayenesinde posterior embryotokson, bilateral displastik böbrek saptanması otozomal dominant geçişli bu hastalıkta AGS tanısını destekliyordu. Noonan sendromunda periferik pulmoner stenoz, renal tutulum olabilir ancak kolestaz beklenen bulgu değil. Di George sendromunda konjenital kalp tutulumu sık görülür ancak hipoparatiroidi beklenir. Axenfeld-Rieger sendromunda posterior embryotokson yanında daha çok yüz ve ağız anomalileri görülür, konjenital kalp hastalıkları ve kolestaz beklenen bulgular değil (21). Genetik polikliniğinden istenen konsültasyonda da AGS tanısı düșünülmüş ve taburculuk sonrası genetik polikliniğine kontrole gelmesi planlanmıştı. Ailenin sosyoekonomik durumu nedeniyle genetik analizinin yapılmamış olması ve uzun süren candida peritoniti nedeniyle kolestazın ayırıcı tanısına yönelik karaciğer biyopsisinin yapılmamış olması olgumuzun kısıtlılığını oluşturuyordu.

Alagille sendromu genellikle tipik yüz görünümü, karaciğer tutulumu, konjenital kalp hastalığı, iskelet anomalisi ile prezente olur. Bizim olgumuz, daha nadir saptanan bilateral displastik böbreğe bağl1 kronik böbrek yetmezliği ile birlikte olan AGS olması nedeniyle sunmak istedik. 


\section{KAYNAKLAR}

1. Turnpenny PD, Ellard S. Alagille syndrome: pathogenesis, diagnosis and management. Eur J Hum Genet 2012;20:251-257

2. Hoffenberg EJ, Narkewicz MR, Sondheimer JM, et. Al. Outcome of syndromic paucity of interlobular bile ducts (Alagille syndrome) with onset of cholestasis in infancy. J Pediatr 1995;127:220-4.

3. Subramaniam P, Knisely A, Portmann B, Qureshi SA, Aclimandos WA, Karani JB, Baker AJ. Diagnosis of Alagille syndrome-25 years of experience at King's College Hospital. J Pediatr Gastroenterol Nutr 2011;52:84-9.

4. Emerick KM, Rand EB, Goldmuntz E, Krantz ID, Spinner NB, Piccoli DA. Features of Alagille syndrome in 92 patients: frequency and relation to prognosis. Hepatology 1999;29:822-9.

5. Krantz ID, Smith R, Colliton RP, et al.Jagged1 mutations in patients ascertained with isolated congenital heart defects. Am J Med Genet 1999;84:5660.

6. Krantz ID,Piccoli DA,Spinner NB. Alagille syndrome. J Med Genet. 1997;34:152-157.

7. McDonald- McGinn DM, Kirschner R, Goldmuntz E, et.al. The Philidelphia story: the 22q11.2 deletion. Report on 250 patients. Genet Couns 1999; 10:11-24.

8. Berrocal T, Gamo E, Navalón J, et al. Syndrome of Alagille: radiological and sonographic findings. A review of 37 cases. Eur Radiol 1997;7:115-118.

9. Kamath BM, Stolle C, Bason L, et al. Craniosynostosis in Alagille syndrome. Am J Med Genet. 2002;112:176-180.

10. Ryan RS, Myckatyn SO, Reid GD, Munk P. Alagille syndrome: case report with bilateral radio-ulnar synostosis and a literature review. Skeletal Radiol 2003;32:489-91.

11. Kamath BM, Podkameni G, Hutchinson AL, Leonard LD, Gerfen J, Krantz ID, et al. Renal anomalies in Alagille syndrome: a disease-defining feature. Am J Med Genet 2012;158:85-9.
12. Trem WR, Krzymowski GA, Cartun RW, et. al. Cytokeratin immunohistochemical examination of liver biopsies in infant with Alagille syndrome and biliary atresia. J. Pediatr Gastroenterol Nutr 1992; 15:73-80.

13. Wolfish NM, Shanon A. Nephropathy in arteriohepatic dysplasia. Child Nephrol Urol 19881989;9:169-72.

14. Hirai H, Santo Y, Kogaki S, Kurotobi S, Etani Y,Mushiake S, Nakatsuchi Y, Nakajima S, Ozono $K$. Successful stenting for renal artery stenosis in a patient with Alagille syndrome. Pediatr Nephrol 2005:831-3.

15. Tolia V, Dubois RS, Watts FB Jr, Perrin E. Renal abnormalities in paucity of interlobular bile ducts. $J$ Pediatr Gastroenterol Nutr 1987;6:971-976.

16. Chung-Park M, Petrelli M, Tavill AS. et. al. Renal lipidosis associated with arteriohepatic dysplasia. Clin Nephrol 1982; 18:314-20.

17. Oda T, Elkahloun AG, Pike BL, Okajima K, Krantz ID, Genin A, Piccoli DA, Meltzer PS, Spinner NB, Collins FS,et al. Mutations in the human Jaggedl gene are responsible for Alagille syndrome. Nat Genet. 1997; 16:235-242.

18. McDaniell R, Warthen DM, Sanchez-Lara PA, Pai A, Krantz ID, Piccoli DA, Spinner NB. NOTCH2 mutations cause Alagille syndrome, a heterogeneous disorder of the notch signaling pathway. Am J Hum Genet. 2006; 79:169-173.

19. David A. Picolli. Alagille syndrome. In: F.J. Suchy, R.J. Sokol, W.F. Ballstrerl(eds.) Liver Disease In Children 2nd edition. Phildelphia: Lippincott,Williams \&Wilkins; 2001.p.327-42.

20. Brodsky MC, Cunniff C. Ocular anomalies in the Alagille syndrome (arteriohepatic dysplasia) Ophthalmology. 1993;100:1767-1774.

21. Espinoza, H, Cox CJ, Semina, EV, Amendt BA. $A$ molecular basis for differential developmental anomalies in Axenfeld-Rieger syndrome. Hum Molec Genet. 2002;11: 743-53. 